\title{
Adaptation of the Application of the Authentic Assessment Model During the Covid-19 Pandemic
}

\author{
Suciati Rahayu Widyastuti \\ Universitas Nahdlatul Ulama Cirebon, Cirebon, Jawa Barat, 45111, Indonesia \\ Corresponding author: suciati.rahayu@student.upi.edu
}

\begin{abstract}
During the Covid-19 pandemic, the education sector must adapt to new habits. Student assessments also adapt to the learning process that is carried out online. This is a challenge for the school and especially for educators and students. This study used 200 grade 7 student's from 8 State Junior High Schools in a city in West Java Province as samples. The school is assumed to have used authentic assessment because it has used the 2013 Curriculum. The research method used a descriptive qualitative method. The data collection technique was done using a closed questionnaire and interviews. The questionnaire consisted of 15 statements regarding the learning process and assessment during online learning. The questionnaire was given to students online with the permission of the school and supervised by the teacher and parents or guardians of the student. The results showed: 1 . The teacher continued to socialize the authentic assessment process well; 2 . The teacher continues to flexibly carry out authentic assessments; 3 . The teacher continues to master the material on authentic assessment. Attitude assessment based on online presence and student responses to the assignment given. Meanwhile, the psychomotor assessment of students is carried out if there is a task with a demonstration that is recorded on video and sent to the teacher. For peer-to-peer assessments, it is difficult to do because students cannot meet in person.
\end{abstract}

Keywords: Adaptation, Authentic Assessment, Covid-19 Pandemic.

\section{INTRODUCTION}

Adaptation is what is needed when dealing with new and unusual conditions. In early 2020 all parts of the world experienced the Covid-19 pandemic. The government requires student learning activities in schools. Public and private schools are required to have implemented the 2013 Curriculum since 2014. The 2014 curriculum in its assessment uses authentic assessment. The authentic assessment offers a more realistic assessment because the assessment describes the increase in student learning in each learning process. Authentic research is defined by Callison (2014) as an assessment process that various performances that reflect how students learn, achievement, motivation, and attitudes related to learning activities [1].
According to Wiggins (1989), authentic assessments have characters that are designed to truly represent performance in the field and these assessments attempt to evaluate the "important things" of performance with articulated performance standards that can be openly disclosed to students and others in the learning community, and not kept secret in the content-based exam tradition. This criterion is a standard because it is based on explicit and diverse school goals, representing various aspects of the task [2].

The difference between the characteristics of authentic assessment and traditional assessment is that authentic assessment is an assessment that is performing a task, real-life, construction/application, studentstructured, and direct evidence. Meanwhile, traditional assessment has the characteristics of selecting a 
response, contrived, recall /recognition, teacherstructured, and independent evidence.

Types of authentic tasks, namely the selectedresponse in the form of Multiple-choice tests, True-false, Matching, Fill-in-the-blank, and Label a diagram. Constructed responses are students compiling answers from old and new knowledge, because there is no one definite answer to this clue, students build new knowledge that may be slightly different from those constructed by other students. Examples of constructed responses are short-answer essay questions, concept maps, making predictions, journal responses, selfassessment. Product is a type of task that requires students to build substantial and tangible products that express their understanding of certain concepts and skills and/their ability to apply, analyze, synthesize, or evaluate these concepts and skills. Examples of products are essays, stories, poems, ballads, metaphors, book reviews, and surveys. Performance is a task for students who are required to build performances that reveal their understanding of certain concepts and skills and/or their ability to apply, analyze, synthesize, or evaluate those skills and concepts. Examples of assignments from performance musical audition, conducting an ensemble, dramatic reading, book talks, and panel discussion. [3].

Of these types of authentic assessment tasks, not all of them can be applied as they were during the learning process before the Covid-19 pandemic. Because some must be assessed in a face-to-face manner and require interaction among students. For this reason, teachers and students must adapt the assignments from which authentic assessments can still be given by students. Then how do they adapt, and whether the delivery of authentic assessment tasks is conveyed well?.

\section{METHOD}

Research areas: State Junior High Schools in Cities in West Java Province, Indonesia. Geographically, West Java Province in the west is bordered by the Sunda Strait, in the north by the Java Sea and the Special Capital Region of Jakarta, in the east is bordered by Central Java Province and in the south is bordered by the Indonesian Ocean. The full geographic location is Longitude: $104^{\circ} 8$ '- $^{\circ} 108^{\circ} 41^{\prime} \mathrm{E}$ and Latitude: $5^{\circ} 50^{\prime}$ $7^{\circ} 50^{\prime} \mathrm{LS}$. On the Rupa Bumi map of Indonesia. (FIGURE 1)

Field mapping observation $\&$ preparation: This research method has two steps, namely the observation of the online learning process and distributing questionnaires to students. Observations of the learning process consist of observations using any media for the student's online learning process, how students respond to authentic assessment assignments that are given online, and what authentic assessment assignments cannot be given to students during online learning.

Sampling method: The sampling method in the research area is 2007 th grade students of 8 State Junior High Schools in a city in West Java Province. Sampling was taken from grade 7 students because these students were junior high school students who had never really studied face-to-face since the new teaching began. Sampling is done randomly from the number of the existing population using the Slovin calculation technique because the population is more than 1,000 . Every 7th grade in the State Junior High School has the same opportunity to be a sample.

Preparation method: Preparation for the study begins with validating the questionnaire that the researcher will use to collect data from the main subject, namely students. Choosing State Junior High Schools that still apply authentic assessment. Likert scale calculation on the results of student questionnaires using tiered categorization [4] is divided into 3 categories, namely low, medium, and high. Low category if the score is less than 200, medium category if the score is between 200 to 500, high category if the score is more than 750 .

\section{RESULTS AND DISCUSSION}

West Java Province when depicted on the map will be like this:

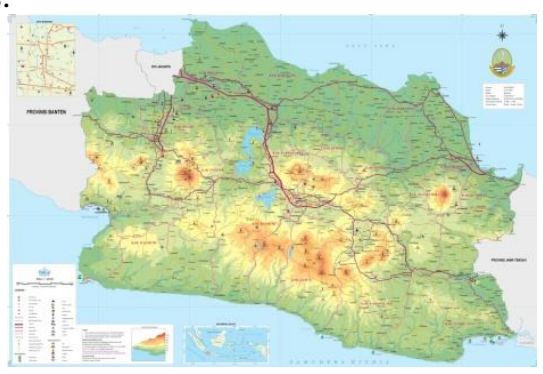

FIGURE 1. Geological Map of West Java, Indonesia

The calculation of the questionnaire data given to students is calculated. The results of the calculation of five indicators are 1 . The teacher socializes the authentic assessment task well; 2 . The teacher gives a variety of authentic assessment assignments; 3. The teacher mastered the material about authentic assessment. 4. Students do authentic assessment tasks following referrals; 5. Students expect feedback from authentic assessments. The questionnaire has a choice weighted score as follows: Strongly Agree (4), Agree (3), Disagree (2), and Disagree (1). The scale component was adapted from the Likert scale [5]. Following are the results of calculating the questionnaire data regarding the adaptation to the application of authentic assessment: 


\begin{tabular}{l|l|c|c} 
No & \multicolumn{1}{|c|}{ Indicator } & Score & Category \\
\hline 1. & Teachers socialize authentic assessment tasks well. & 651 & High \\
\hline 2. & The teacher gives a variety of authentic assessment tasks & 606 & High \\
\hline 3. & The teacher mastered the material about authentic assessment & 589 & High \\
\hline 4. & Students work on authentic assessment tasks following instructions & 682 & High \\
\hline 5. & Students expect feedback from authentic assessments & 654 & High
\end{tabular}

Figure 2. Data from students' questionnaire results.

Categories are determined based on the following calculations: choices Strongly Agree (4), Agree (3), Disagree (2), and Strongly Disagree (1). The range is obtained from the maximum score - the minimum score which is $200 \times 1=100$ this is the minimum score, $200 \times 4$ $=800$ is the maximum score. So the range is $800-200=$ 600.Thus each unit standard deviation is $\sigma=600 / 6=$ 100 (divided by 6 because a normal distribution is divided into 6 standard deviation units), and the theoretical mean is $\mu=200 \times 1.5=350$. ( 1.5 comes from the maximum response score - the minimum response score is halved or $1.5=(4-1) / 2)$. If we want to classify the subject into 3 categories of achievement motivation diagnosis, we divide the six standard deviation units into 3 parts. Becomes:

$\begin{array}{ll}X<(\mu-1,0 \sigma) & \text { Low } \\ (\mu-1.0 \sigma) \leq X<(\mu+1,0 \sigma) & \text { Moderate } \\ (\mu+1,0 \sigma) \leq X & \text { High }\end{array}$

So that with the price $\sigma=4$, the score categories for Achievement Motivation are as follows:
$\mathrm{X}<[350-1.5(100)]$
$[350-1.5(100)] \leq X<[350+1.5(100)]$
Low
$[350+1.5(100)] \leq X$
Moderate
The result:
$\mathrm{X}<200$
High
$200 \leq X<500$
$500 \leq X$
Low
Moderate
High

\section{CONCLUSIONS}

The results showed that the teacher was still able to socialize the authentic assessment task properly, seen from the score which showed that all the indicators had a high category from the questionnaire given to students, the teacher when giving authentic assessment assignments was also varied although not as complex as usual, and the teacher still mastered the assignment material. authentic assessment. Then when viewed from the learning process and student responses to authentic assessments when learning online. Students continue to work on authentic assessment assignments as directed and do not rush. Then students also expect feedback from authentic assessment assignments. Another finding from the teacher's experience was the assessment of attitudes based on online attendance and student responses to assignments. Meanwhile, the student's psychomotor assessment was carried out by assigning a video-recorded demonstration. Assessment between friends is difficult because students do not see each other.

\section{REFERENCES}

[1] Callison, D, "Authentic Assessment of American Association of School Librarians. [online]. Available:

http://www.ala.org/ala/mgrps/divs/aasl/aaslpubsa ndjournals/slmrb/editorschoiceb/infopower/selctc allison85.cfm. [Accessed: Februari. 15, 2015]

[2] Wiggins, G, Teaching to the (authentic) test. Educational Leadership, 1989, 46(7), pp.41-47.

[3] Jon Muellers, Authentic Assessment Toolbox, 2018. [online]. Available: http://jfmueller.faculty.noctrl.edu/toolbox/tasks.h tm\#characteristics. [Accessed: November. 10, 2020]

[4] Azwar, Saifuddin, Penyusunan Tes Skala Psikologi. Yogyakarta :Pustaka Pelajar, pp. 87, 2013.

[5] Charlotte Brasic Royeen, Adaptation of Likert Scaling for Use with Children, 1985. [online]. Availabel:

https://journals.sagepub.com/doi/10.1177/153944 928500500104. [Accessed: November 10, 2020]. 